\title{
Preparación de genotecas de ADNc de Plasmodium falciparum para la búsqueda de los genes de proteínas de unión a calmodulina, GOGAT y Pfmyo A
}

\author{
Dary L. Mendoza ${ }^{1,2}$, Moisés Wasserman ${ }^{1,2}$ \\ ${ }^{1}$ Laboratorio de Bioquímica, Instituto Nacional de Salud, Bogotá, D.C., Colombia. \\ ${ }^{2}$ Laboratorio de Investigaciones Básicas en Bioquímica, LIBBIQ, Departamento de Química, Facultad de \\ Ciencias, Universidad Nacional de Colombia, Bogotá, D.C., Colombia.
}

Se construyó una genoteca de ADNc representativa de los estadios asexuales de Plasmodium falciparum, en el vector $\lambda Z i p L o x$. Esta genoteca (de la cepa colombiana FCB2) y otra genoteca construida en $\lambda Z A P$ II (de la cepa Dd2), se rastrearon en busca de genes de proteínas que se unen a calmodulina ( $\mathrm{CaM})$ o a proteínas relacionadas con CaM. Para el rastreo se usó tanto el ensayo de Hot-start PCR como la hibridización de filtros réplica con sondas radiomarcadas. Se identificaron clones de actina I, calmodulina (CaM), glutamato sintasa (GOGAT) y las tres miosinas Pfmyo A, Pfmyo B y Pfmyo C. Se aislaron clones para actina I, CaM y GOGAT en la genoteca construida en $\lambda Z i p L o x$ y clones para GOGAT y Pfmyo A en la genoteca construida en $\lambda Z A P$ II. Uno de los clones de GOGAT contiene un inserto de 2.413 pb que corresponde al $24,8 \%$ de la secuencia codificante informada. El inserto de Pfmyo A aislado tiene $2.457 \mathrm{pb}$ y representa el mensajero completo del gen. La identidad de este inserto se confirmó mediante análisis de restricción. Este es el primer informe de un clon de ADNc completo de la miosina A de $P$. falciparum. Los clones aislados se utilizarán en estudios futuros, tales como la obtención de las proteínas recombinantes, producción de anticuerpos y ensayos de funcionalidad.

Palabras clave: Plasmodium falciparum, malaria, proteína de unión a calmodulina, glutamato sintasa, miosina, ADNc.

Screening for calmodulin, GOGAT and Pfmyo A genes in Plasmodium falciparum cDNA libraries

A cDNA library of Plasmodium falciparum (Colombian strain FCB2) asexual stage was constructed in the $\lambda$ ZipLox vector. The $\lambda$ ZipLox library and a $\lambda$ ZAPII (Dd2 strain) were screened for genes coding for proteins that bind with or are related to calmodulin $(\mathrm{CaM})$. Screening was accomplished with Hot start PCR assays and hybridization with radiolabeled probes. Actin I, CaM, glutamate synthase (GOGAT) and the three myosin clones -Pfmyo A, Pfmyo B and Pfmyo C- were identified. The clones coding for actin I, CaM and GOGAT were retrieved from the $\lambda$ ZipLox library, and the GOGAT and Pfmyo A clones from the $\lambda$ ZAP II library. The GOGAT clone contained an insert of 2,413 base pairs corresponding to $24.8 \%$ of the reported sequence. The Pfmyo A insert was 2,457 base pairs long, and represented the complete mRNA coding for this gene. Finally, the first report of a complete cDNA clone containing the $P$. falciparum myosin $A$ is presented.

Key words: Plasmodium falciparum, malaria, calmodulin binding protein, glutamate synthase, myosin, cDNA.

Correspondencia:

Moisés Wasserman: mwasserman@hemagogus.ins.gov.co

Recibido: 12/02/02; aceptado: 11/08/02
Plasmodium falciparum es un parásito perteneciente al filo de los Apicomplexa y el causante de la forma más severa de malaria humana. El parásito tiene un ciclo de vida complejo durante el cual es transmitido entre el 
mosquito vector y el hombre. A pesar de que los eventos morfológicos que ocurren en la invasión están bien caracterizados, se sabe poco sobre los mecanismos moleculares que producen estos cambios y la naturaleza de los mensajeros químicos que median la comunicación entre las células huésped y el parásito.

El sistema calcio/calmodulina ( $\mathrm{CaM}$ ) cumple un papel muy importante en la maduración y la invasión del parásito al eritrocito (1); los estudios realizados en nuestro laboratorio indican que es necesaria una entrada transitoria de calcio para activar los eventos moleculares que conducen a la invasión (2). Se cree que el influjo de calcio en el glóbulo rojo puede activar a la CaM o a las PUCaM (proteínas de unión a calmodulina) y, en consecuencia, activar procesos regulados por el calcio relacionados con el crecimiento del parásito (3). Muchas PUCaM están involucradas en la regulación de actividades celulares fundamentales en el citoplasma y la membrana plasmática de las células. Algunas PuCaM dependientes de calcio están relacionadas con sistemas de movilidad mediados por actina, como la alfa-espectrina, la cadena liviana de la miosina y la caldesmon; otras están involucradas en la fosforilación y desfosforilación de proteínas, como la proteína cinasa II dependiente de CaM y la proteína fosfatasa calcineurina dependiente de CaM (4). También se ha implicado la participación de estas proteínas en la regulación de la expresión de genes de proteínas del citoesqueleto (5), en la replicación, transcripción y reparación del ADN y en la regulación del ciclo celular (6). Hay parásitos, como Trypanosoma cruzi (7), para los que se han informado complejos perfiles de PUCaM que se expresan diferencialmente en sus estadios celulares.

Recientemente, se aislaron en $P$. falciparum por cromatografía de afinidad sobre columnas de CaM-agarosa, nueve proteínas del citoesqueleto que se unen a CaM (8). Una de estas proteínas, que tiene un peso molecular de $36,5 \mathrm{kDa}$, se pudo secuenciar parcialmente y mediante PCR con oligonucleótidos degenerados, diseñados con base en secuencias peptídicas internas de la proteína; se obtuvo un fragmento de 454 pb que presentó una alta homología con la secuencia nucleotídica para la glutamato sintasa (GOGAT) de origen vegetal. En algunos microorganismos y en la mayoría de las plantas superiores, la asimilación de amonio en nitrógeno orgánico es el resultado de la actividad de dos enzimas, la glutamina sintetasa (GS) y la glutamato sintasa (GOGAT). La GS cataliza la incorporación de amonio en la posición amida del glutamato para producir glutamina. Por su parte, la GOGAT cataliza la transferencia reductiva del grupo amido de la glutamina a la posición $\alpha$-ceto del 2oxoglutarato, produciéndose dos moléculas de glutamato (9). El resultado de la reacción catalizada por estas dos enzimas es similar al producido por la glutamato deshidrogenasa, excepto por el gasto de una molécula extra de ATP por cada glutamato que se produce.

En algunas especies de Plasmodium se ha identificado la actividad de la glutamato deshidrogenasa $(10,11) \mathrm{y}$, recientemente, se ha planteado la hipótesis de que la GOGAT participa en la interconversión de L-glutamina a glutamato (12). Hasta ahora, únicamente se conoce la secuencia informada del ARNm de GOGAT de $P$. falciparum; de aquí la importancia de tener un clon que sirva como herramienta para estudios futuros de funcionalidad de la proteína.

Otras de las PUCaM de interés en $P$. falciparum son las miosinas. Éstas constituyen una diversa superfamilia de mecanoenzimas que en actividad conjunta con la actina están involucradas en muchos movimientos celulares esenciales. C. Forero (13) y Pinder y col. (14) con el método descrito por Bement y col. (15) lograron evidenciar la existencia del gen de la miosina $A$ de $P$. falciparum (Pfmyo-A). Ésta es una proteína de $\sim 90 \mathrm{kDa}$, correspondiente a las miosinas de clase XIV; se expresa esencialmente en los estadios maduros del desarrollo asexual y se cree que podría estar participando como motor molecular en el proceso de invasión al eritrocito, puesto que se expresa en el sitio y momento propicio de la invasión (16). Con base en el proyecto de secuenciación del genoma de $P$. falciparum se identificaron recientemente tres miosinas más, llamadas Pfmyo-B (17), Pfmyo-C y Pfmyo D (18).

El propósito del presente trabajo fue obtener una genoteca de ADNc representativa de los estadios 
de vida asexual del parásito $P$. falciparum y aislar en ella clones de los genes de las PUCaM, GOGAT y Pfmyo A, para la caracterización futura de las proteínas.

\section{Materiales y métodos \\ Cultivo del parásito}

Se hicieron cultivos continuos con la cepa FCB2 de $P$. falciparum (aislada en Colombia) según el método de Trager y Jensen (19). La cepa de $P$. falciparum se cultivó en medio RPMI (Sigma), suplementado con suero humano al 10\% (v/v) y eritrocitos tipo $\mathrm{O}(+)$ al $5 \%$. Se recogieron parásitos asincrónicos enriquecidos en formas maduras y con parasitemias que fluctuaron entre 4 y $5 \%$.

\section{Aislamiento del ARN total y separación del ARNm}

Los parásitos se liberaron del eritrocito mediante lisis con saponina al $0,15 \%$ w/v en HBS (Hepes $20 \mathrm{mM}, \mathrm{NaCl} 60 \mathrm{mM}), \mathrm{pH} \mathrm{7,4,} \mathrm{y} \mathrm{se} \mathrm{recolectaron}$ por centrifugación a $15.000 \mathrm{~g}$ por $20 \mathrm{~min}$ a $4{ }^{\circ} \mathrm{C}$ (Himac centrifuge Hitachi rotor RPR 20-2). El precipitado de parásitos se lavó tres veces con HBS (15.000 g durante 5 min a $4^{\circ} \mathrm{C}$ ).

La extracción del ARN total se hizo siguiendo un protocolo previamente estandarizado en nuestro laboratorio (20), que se fundamenta en la extracción del ARN con isotiocianato de guanidina y posterior separación del ADN y las proteínas a través de un gradiente isopícnico de cloruro de cesio. Se partió de $2 \times 10^{9}$ parásitos, los cuales se lisaron con una mezcla de isotiocianato de guanidina 4M, citrato de sodio $25 \mathrm{mM}(\mathrm{pH}, 7,0)$, sarkosyl al 0,5\% y beta-mercaptoetanol a 0,1 $\mathrm{M}$. El precipitado se resuspendió y homogeneizó con una aguja 20G. La separación de las proteínas se hizo por extracción con un volumen de fenolcloroformo-alcohol isoamílico (25:24:1) y centrifugación a $8.000 \mathrm{~g}$ durante $5 \mathrm{~min}$ a $4^{\circ} \mathrm{C}$. La solución acuosa se agregó lentamente sobre un colchón de $\mathrm{CsCl}$ 5,7 M, EDTA 10 mM. El ARN total se separó por centrifugación a $120.000 \mathrm{~g}$ en un rotor swing (PSGST Hitachi) durante 20 horas a $20^{\circ} \mathrm{C}$. El ARN, que aparece en el fondo del tubo de centrífuga como un precipitado transparente, se resuspendió suavemente en $200 \mu \mathrm{l}$ de Tris-HCl 10 mM (pH 7,4), EDTA 5 mM,
SDS al 0,1 \%. Finalmente, se precipitó y resuspendió en agua libre de RNasa.

Para la separación del ARNm se empleó el método de captura en solución, polyAtract ${ }^{R}$ RNAm Isolation Systems (Promega). La región 3'poliA+ de los ARNm se hibridó con un iniciador oligo (dT) biotinilado. Los híbridos se capturaron usando estraptavidina acoplada a partículas magnéticas. El sobrenadante se descartó y mediante lavados con tampón de alta astringencia (SSC 0,5 X y SSC 0,1 X) se eliminó el ARN no mensajero. El ARNm se eluyó con $250 \mu \mathrm{l}$ de agua libre de RNasa y se precipitó con 0,1 volúmenes de acetato de sodio $3 \mathrm{M}$ y 0,1 volúmenes de isopropanol a $-20^{\circ} \mathrm{C}$ toda la noche. Luego se centrifugó a $12.000 \mathrm{~g}$ durante 10 minutos; el precipitado se lavó con $1 \mathrm{ml}$ de etanol al 75\% y se secó al vacío. Una forma rápida de evaluar la integridad del ARNm fue haciendo RTPCR con secuencias conocidas de $P$. falciparum, como es el caso del gen que codifica para la enzima aldolasa y se obtuvo un resultado positivo (resultados no mostrados).

\section{Síntesis del ADNc}

La síntesis de ADNc se realizó utilizando el sistema de síntesis de ADNc de SuperScripta (Gibco-BRL). Se usaron $3 \mathrm{mg}$ de $A R N m$ que fueron transcritos reversamente usando 1,5 $\mu \mathrm{g}$ del primer-adaptador Not 1, de acuerdo con el método descrito por Gubler y Hoffman (21). La síntesis de la primera y la segunda cadena fue cuantificada por la incorporación de $\left[\alpha^{32} \mathrm{P}\right] \mathrm{dCTP}$ (1 $\mu \mathrm{Ci} / \mu \mathrm{l}$; Amersham-Pharmacia Biotech). El ADNc se trató con la T4 ADN polimerasa para después ligar a sus extremos adaptadores Sall. Después de la extracción fenol-cloroformoalcohol isoamílico, el ADNc se digirió con 100 unidades de Notl y se purificó por cromatografía de filtración en gel, usando una matriz de Sepharose CL-4B. Se eluyó recolectando 16 fracciones, las cuales se leyeron en forma directa en un contador de centelleo (Wallac 1409). Se calculó la cantidad de ADNc en las fracciones que dieron valores por encima de $2 \times 10^{4} \mathrm{cpm}$.

\section{Clonación de ADNc}

Se empleó el vector de expresión procariótico $\lambda$ ZipLox $^{\text {TM }}$ (Gibco-BRL). Este vector permite 
acomodar insertos de hasta $7 \mathrm{~kb}$ de tamaño dentro de brazos de $\lambda$, los cuales poseen extremos Notl y Sall, respectivamente. $\lambda$ ZipLox posee un sistema de recombinación sitioespecífico que permite recuperar los insertos clonados dentro del plásmido pZL 1 mediante un protocolo de excisión in vivo. Las genotecas construidas en el vector $\lambda$ ZipLox se pueden rastrear usando sondas fabricadas a partir de oligonucleótidos o con anticuerpos. Los ADNc clonados dentro del sitio del polylinker del vector residen dentro del gen lac Z'. Cuando el promotor lac es inducido con IPTG, el gen se expresa como una proteína de fusión con la porción aminoterminal del fragmento de la $\beta$-galactosidasa codificada por lacZ'.

Para la construcción de la genoteca se usaron 60-72 ng de ADNc, que se ligaron a los brazos Notl-Sall del vector $\lambda$ ZipLox (200 ng), para luego ser empacados en las cabezas y colas del fago (Gigapack ${ }^{\circledR}$ III Gold Packaging; Stratagene). EI fago se usó en la infección de la cepa huésped de Escherichia coli Y1090 (ZL)® de Promega.

Además de la genoteca de ADNc de la cepa FCB2 de $P$. falciparum, se trabajó con otra genoteca de ADNc, representativa de los estadios de vida asexual, de la cepa Dd2 del parásito (adquirida en el Malaria Research \& Reference Reagent Resource Center, MR4) y construida en el vector $\lambda Z A P I I$ mediante metodología previamente estandarizada (23), y cuyo título fue de $2 \times 10^{5} \mathrm{ufp} / \mathrm{ml}$.

\section{Manejo de la genoteca}

La representatividad de la genoteca se calculó mediante la formula de Clark y Carbon (22), según la cual el número mínimo de clones totales requeridos para construir una genoteca representativa del parásito $P$. falciparum es de 16.942. Adicionalmente, esta representatividad se confirmó mediante la búsqueda por PCR de clones para genes de copia única, como actina I y CaM, utilizando oligonucleótidos específicos (cuadro 1). También se buscaron clones de las PuCaM: GOGAT, Pfmyo A, Pfmyo B y Pfmyo C. Para la búsqueda de un clon de GOGAT, se utilizó como herramienta una pareja de oligonucleótidos específicos diseñados a partir de la secuencia del gen informada en el GENBANK (número de acceso, Y17045.1), los cuales amplifican un fragmento de $811 \mathrm{pb}$ que contiene la secuencia que codifica para la proteína de $36,5 \mathrm{kDa}$ aislada en nuestro laboratorio. Para la búsqueda de clones de las miosinas Pfmyo A, Pfmyo B y Pfmyo $C$ se diseñaron oligonucleótidos específicos para cada gen con base en las secuencias informadas en el GENBANK.

La reacción de amplificación se llevó a cabo usando $1 \mu \mathrm{l}$ de cada genoteca y los siguientes reactivos: oligonucleótidos iniciadores $(1 \mu \mathrm{M}$ de cada uno), dNTPs ( $200 \mu \mathrm{M}$ de cada uno), MgCl2 $2 \mathrm{mM}$ y el tampón de la reacción (Tris- $\mathrm{HCl} 10$ $\mathrm{mM}$ a pH 9,0, KCl $50 \mathrm{mM}$, Triton X-100 al 0,1\% v/ v). Las condiciones de la reacción de PCR fueron las siguientes: 1 ciclo de $95^{\circ} \mathrm{C}$ durante 10 minutos y $72{ }^{\circ} \mathrm{C}$ durante 5 minutos con adición de 2,5 unidades de Taq ADN polimerasa, seguido de 40 ciclos como sigue: temperatura de denaturación a $94{ }^{\circ} \mathrm{C}$ durante 2 minutos, temperatura de anillamiento del oligonucleótido a $53{ }^{\circ} \mathrm{C}$ durante 1 minuto y temperatura de extensión a $72{ }^{\circ} \mathrm{C}$ durante 2 minutos. Los productos de PCR se separaron por electroforesis horizontal y se visualizaron mediante tinción con bromuro de etidio $(0,5 \mu \mathrm{g} / \mathrm{ml})$. La electroforesis se hizo en geles de agarosa al $1 \%$ en TBE (Tris base $890 \mathrm{mM}$; ácido bórico, $890 \mathrm{mM}$; EDTA 20 $\mathrm{mM}$ a pH 8,0). La corrida se hizo a un voltaje de $5 \mathrm{~V} / \mathrm{cm}$ y el gen se sometió a tinción con bromuro de etidio de 10 a 20 minutos y se observó con luz UV.

\section{Rastreo y aislamiento de los clones de PuCaM}

El rastreo de los clones de GOGAT y de Pfmyo A se hizo mediante el ensayo de hibridación de filtros réplicas con sondas de oligonucleótidos marcadas radiactivamente con ${ }^{32} \mathrm{P}$ y con actividades específicas de en un rango de entre 2 y $7 \times 10^{9} \mathrm{cpm} / \mu \mathrm{g}$ de $A D N$. Los filtros réplica se hicieron a partir de cajas sembradas con $2 \times 10^{4}$ ufp. Una vez hecha la búsqueda inicial, se seleccionaron las señales de los posibles clones recombinantes para cada gen y se confirmaron por PCR. Se hicieron tres rondas sucesivas de selección con el fin de obtener clones puros.

Se preparó un lisado de fagos a partir de un cultivo líquido de bacterias E. coli competentes, infectadas con los fagos que tienen el clon puro. 
Cuadro 1. Secuencias de los oligonucleótidos diseñados para cada gen y tamaños de los fragmentos amplificados sobre ADN genómico de P. falciparum.

\begin{tabular}{|c|c|c|c|}
\hline $\begin{array}{l}\text { Gen (código } \\
\text { GENBANK) } \\
\text { fraqmento }\end{array}$ & $\begin{array}{c}\text { Secuencia del oligo } \\
\text { sentido }\end{array}$ & $\begin{array}{l}\text { Secuencia del oligo } \\
\text { antisentido }\end{array}$ & Longitud del \\
\hline
\end{tabular}

(pb)

\begin{tabular}{|c|c|c|c|}
\hline $\begin{array}{l}\text { Actina I } \\
\text { (Af177282) }\end{array}$ & ACAGGAGTTGCAGGAGATGAT & GTAGTTGTGTGGATTCCTGC & 800 \\
\hline $\begin{array}{l}\text { CaM } \\
\text { (M99442) }\end{array}$ & GGGTATCATCATTTTAACAAAC & GTAGTTGTGTGGATTCCTGC & 190 \\
\hline $\begin{array}{l}\text { GOGAT } \\
(\mathrm{Y} 17045)\end{array}$ & AGAAGGAGGAGAAGCAGAAG & GTAGTTGTGTGGATTCCTGC & 811 \\
\hline $\begin{array}{l}\text { Pfmyo A } \\
\text { (AF105117) }\end{array}$ & TCCTCCTTCTGGTTCAATTCTTG & GTATTCAATTAGAGGTCCTTCC & 725 \\
\hline $\begin{array}{l}\text { Pfmyo B } \\
\text { (Af22716) }\end{array}$ & GGGTGGTAAATCTAATTGTAGTG & CTGATTCAATTAGAGAGGTCCTTCC & 440 \\
\hline $\begin{array}{l}\text { Pfmyo C } \\
\text { (Af222717) }\end{array}$ & GGTAATAATACGCATGATGATCC & GAGTAACAACTTATTCGACATGC & 453 \\
\hline
\end{tabular}

El ADN del fago se obtuvo a partir de este lisado utilizando el estuche Wizard Lambda Prepsä (Promega).

\section{Cálculo del tamaño de los insertos clonados de GOGAT y Pfmyo A}

El tamaño de los insertos clonados se calculó mediante PCR con oligonucleótidos de los promotores T7 (Promega) y pUC-M13 (Promega), que flanquean el lugar de inserción, en el caso de clones de la genoteca de la cepa FCB2, y con los oligonucleótidos de los promotores T7 y T3 para los clones de la genoteca de la cepa Dd2. También se hizo digestión del ADN de los fagos recombinantes con endonucleasas de restricción que flanquean los insertos clonados.

\section{Southern blotting}

Se hizo confirmación de los insertos mediante Southern blotting con sondas marcadas por PCR con 14-biotín dCTP. Los geles de agarosa se transfirieron a membranas de nylon (Hybondä N; Amersham) mediante protocolo previamente estandarizado. Las membranas se prehibridaron durante 2 horas a $42{ }^{\circ} \mathrm{C}$ con una solución que contiene: formamida al $50 \% \mathrm{v} / \mathrm{v}$, SSC $5 \mathrm{X}$, fosfato de sodio $20 \mathrm{mM}$ ( $\mathrm{pH} 6,5)$, solución Denhardt al $5 \%$ (Ficoll 400 al 0,2\% p/v, polivinilpirrolidona al $0,2 \% \mathrm{p} / \mathrm{v}$, albumina sérica bovina al $0,2 \% \mathrm{p} / \mathrm{v}$ ) y
ADN de esperma de salmón denaturado a una concentración final de $0,5 \mathrm{mg} / \mathrm{ml}$. Luego, las membranas se hibridaron toda la noche a $42{ }^{\circ} \mathrm{C}$ con la misma solución a la que se le agregó 0,1 a $0,5 \mu \mathrm{g}$ de la sonda biotinilada denaturada. Para la detección de las señales, se siguió el siguiente protocolo: la membrana se lavó con soluciones de baja astringencia (SSC 2X, SDS al 0,1\%) a temperatura ambiente para remover el exceso de la sonda y con una solución de alta astringencia (SSC $0,2 \mathrm{X}$, SDS $0,1 \%$ ) a $50{ }^{\circ} \mathrm{C}$ para eliminar las inespecificidades. La membrana se bloqueó con una solución de BSA al 3\% en TBS p/v a $68^{\circ} \mathrm{C}$ durante 1 hora. Luego se hizo la unión al conjugado estreptavidina-fosfatasa alcalina $(1 \mu \mathrm{g} / \mathrm{ml})$ en TBS durante 15 minutos, seguido de lavados con TBSTween 20 al 0,1\% v/v. Las señales se visualizaron con NBT (nitroblue tetrazolium) y BCIP (5-bromo4-cloro-3-indol-fosfato).

\section{Secuencia parcial del inserto de GOGAT}

Con el fin de confirmar la identidad del clon se hizo secuenciación del inserto. La secuencia se realizó en el Laboratorio de Fisiología Molecular del Instituto Nacional de Salud, utilizando el estuche Big Dye Terminator y el secuenciador ABI PRISM 310 (Applied Biosystems), que detecta moléculas marcadas con fluorocromos. La reacción química se basa en el método del dideoxi desarrollado por Sanger y col. (24). La 
secuencia del inserto se comparó con la informada para el ARNm de GOGAT de $P$. falciparum (GENBANK Y17045), a través del programa BLAST (Basic Local Alignment Search Tool).

\section{Resultados}

\section{Construcción de la genoteca de ADNc}

Con el objetivo de obtener clones de ADNc de las proteínas GOGAT y Pfmyo A se construyó una genoteca de ADNc en el vector de expresión procariotico $\lambda$ ZipLox a partir de ARNm aislado de parásitos asincrónicos de la cepa colombiana de $P$. falciparum, FCB2. Este ARNm se usó para la síntesis de ADNc. En cuanto a los rendimientos obtenidos durante la síntesis del ADNc, al final se obtuvo 229 ng de ADNc, lo que permitió hacer dos clonaciones, una de las cuales dio origen a una genoteca cuyo título superó dos veces el valor mínimo de clones recombinantes requerido para una genoteca representativa del parásito, por lo que se utilizó para la búsqueda y aislamiento de los genes de interés.

\section{Identificación de clones de PuCaM}

Mediante PCR, en total se pudo identificar la presencia de tres clones en la genoteca de la cepa FCB2 de $P$. falciparum y seis clones en la genoteca de la cepa Dd2 del parásito. Se identificaron clones para los genes de actina I, calmodulina (resultados no mostrados) y GOGAT en ambas genotecas de ADNc (figura 1). Además, se identificaron clones para las miosinas Pfmyo A, Pfmyo B y Pfmyo C en la genoteca de $A D N c$ de la cepa Dd2 (figura 2). Los clones para los genes de actina I, CaM, GOGAT y Pfmyo A se aislaron mediante hibridación de filtros réplica, obtenidos de las cajas de cultivo con sondas radiactivas marcadas con $\left[\alpha-{ }^{32} \mathrm{P}\right] \mathrm{dCTP}$.

\section{Cálculo del tamaño del inserto de GOGAT}

La reacción de PCR con los oligonucleótidos de los promotores T7 y pUC M13 sobre el ADN del fago recombinante $\lambda$ ZipLox-GOGAT dio un producto de $1.540 \mathrm{bp}$ de los cuales 175 corresponden al vector. Esto indica que el clon aislado de la genoteca de la cepa FCB2 contiene insertos de $1.365 \mathrm{pb}$, aproximadamente. Se aislaron, además, clones de GOGAT en una genoteca de ADNc representativa de los estadios asexuales de la cepa Dd2 del parásito. El tamaño del inserto presente en este clon se estimó por PCR con los oligonucleótidos de los promotores T7 y T3; el resultado fue un producto de 2.550

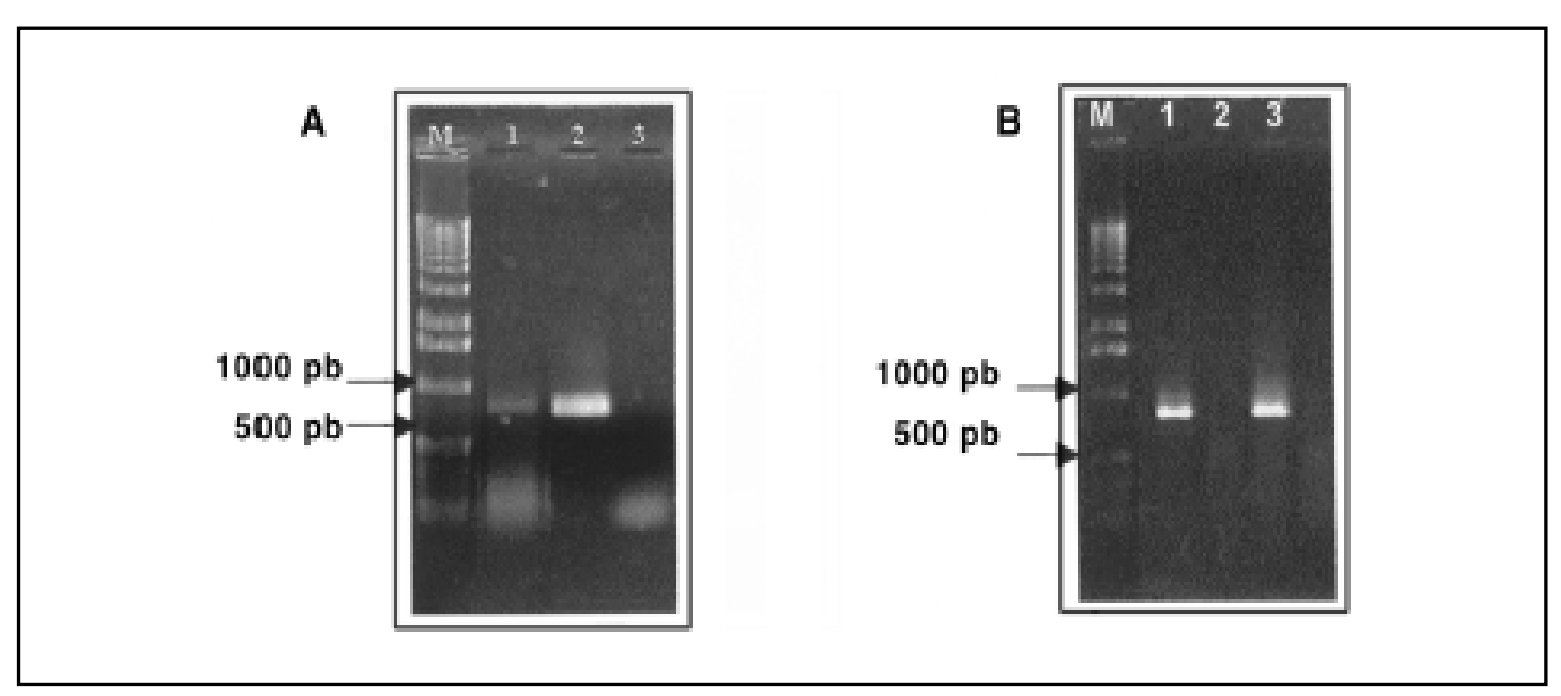

Figura 1. Resultados obtenidos del PCR realizado para identificar la presencia de clones de GOGAT en las genotecas de ADNc. Un volumen de $1 \mu \mathrm{l}$ de cada genoteca se sometió a una reacción de PCR usando oligonucleótidos específicos que amplifican para un producto de $811 \mathrm{pb}$ de GOGAT. A. Búsqueda del clon en la genoteca de la cepa FCB2. B. Búsqueda en la genoteca de la cepa Dd2.

M: marcador de peso molecular Ladder de $1 \mathrm{~kb}$; 1) amplificado sobre la genoteca completa de ADNc; 2) control positivo sobre ADN genómico de FCB2; 3) control negativo del PCR sin ADN. 
$\mathrm{pb}$, de las cuales $135 \mathrm{pb}$ corresponden al vector. La identidad de este inserto se confirmó por Southern blotting con una sonda biotinilada de $811 \mathrm{pb}$, cuya identidad había sido previamente comprobada por secuenciación (figura 3).

\section{Secuenciación parcial del inserto de GOGAT}

Se lograron secuenciar $144 \mathrm{pb}$ del extremo $5^{\prime}$ y $101 \mathrm{pb}$ del extremo 3' de la secuencia parcial del clon de GOGAT aislado de la genoteca de la cepa Dd2 del parásito. Este resultado permitió confirmar la identidad del clon, definir el tamaño del inserto y su posición con respecto a la secuencia codificante completa del gen reportada en el GENBANK y que tiene un tamaño de 9.720 $\mathrm{pb}$. El inserto clonado tiene un tamaño de 2.413 $\mathrm{pb}$, que es el $24,8 \%$ de la secuencia informada y se encuentra entre las posiciones 2.384 y 4.797 de ésta. El alineamiento entre las secuencias de los extremos 5' y $3^{\prime}$ del inserto con la secuencia informada en el GENBANK mostró una identidad del 98 y del $81 \%$, respectivamente (figura 4). Hay que tener en cuenta que durante la secuenciación se generan errores en la lectura de algunas bases, lo que se traduce en disminución en los porcentajes de identidad de los alineamientos entre secuencias (acá, por ser sólo una confirmación, se secuenció una vez y para cada extremo una sola cadena). Finalmente, la digestión del ADN del fago recombinante $\lambda Z A P I I-$ GOGAT con las enzimas de restricción EcoRI y Xhol mostró un patrón de bandas que concuerda con el análisis de restricción teórico realizado sobre la secuencia codificante del gen con estas enzimas (figura 5).

\section{Cálculo del tamaño del inserto de Pfmyo A}

Se hizo PCR con los oligonucleótidos externos de los promotores T7 y T3 para calcular el tamaño del inserto de Pfmyo A clonado. No se obtuvo ningún producto con éstos, pero se logró amplificación con T3 y un oligonucleótido interno sentido de Pfmyo A, al igual que con T7 y un oligonucleótido interno antisentido de Pfmyo $A$. Este experimento permitió calcular el tamaño del inserto en aproximadamente $2.500 \mathrm{pb}$. La identidad de estos productos se confirmó por Southern blotting con una sonda biotinilada de $725 \mathrm{pb}$, cuya identidad había sido previamente comprobada por secuenciación (figura 6).

Se hizo, además, digestión del ADN del fago recombinante de Pfmyo A con las endonucleasas de restricción EcoRI-XhoRl y con Notl- Xhol. La digestión con EcoRI-Xhol produjo tres fragmentos

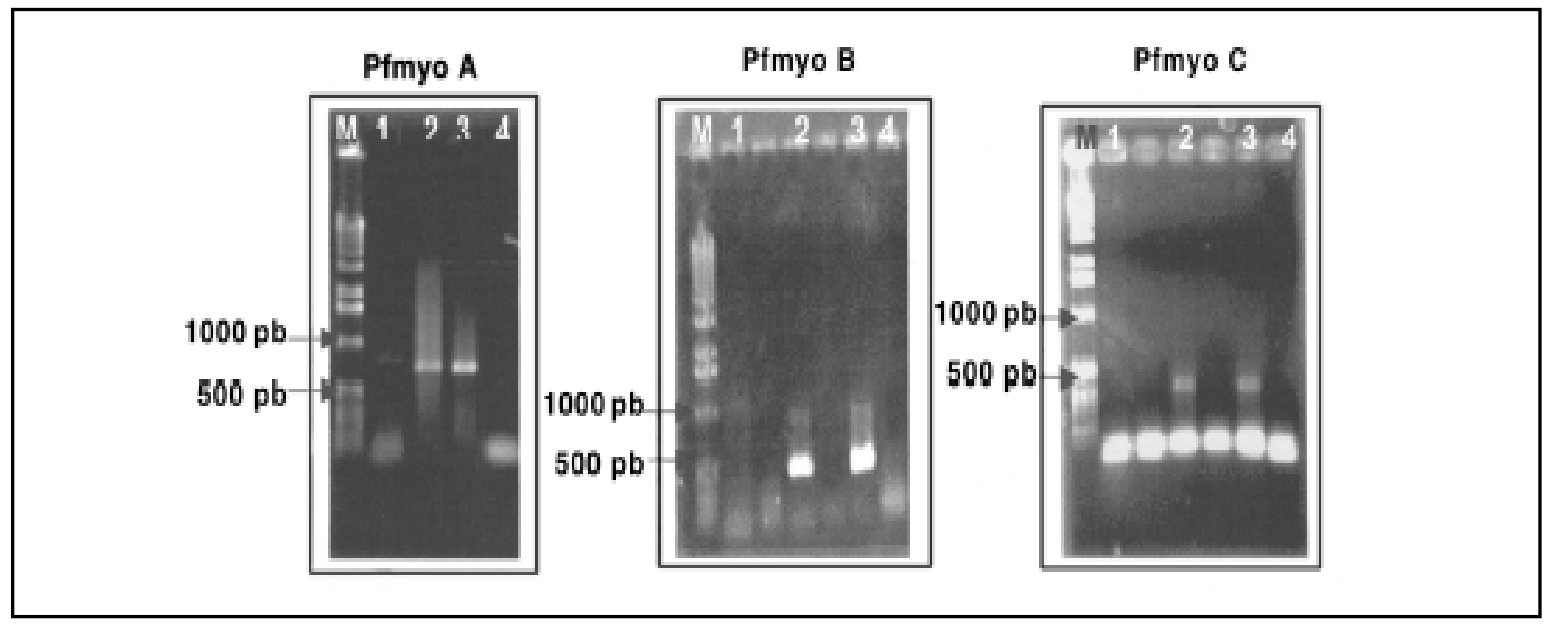

Figura 2. Resultados obtenidos del PCR realizado para identificar la presencia de clones de miosinas Pfmyo A, Pfmyo B y Pfmyo $\mathrm{C}$ en las genotecas de ADNc. Para la búsqueda de clones de Pfmyo A se utilizaron oligonucleótidos específicos que amplifican un producto de 725 pb; los oligonucleótidos para Pfmyo B amplifican un producto de 440 pb y los de Pfmyo C, un producto de $453 \mathrm{pb}$.

M: marcador de peso molecular Ladder de $1 \mathrm{~kb}$; 1) amplificado sobre la genoteca de ADNc de la cepa FCB2; 2) sobre la genoteca de ADNc de la cepa Dd2; 3) control positivo sobre ADN genómico de FCB2; 4) control negativo del PCR. 


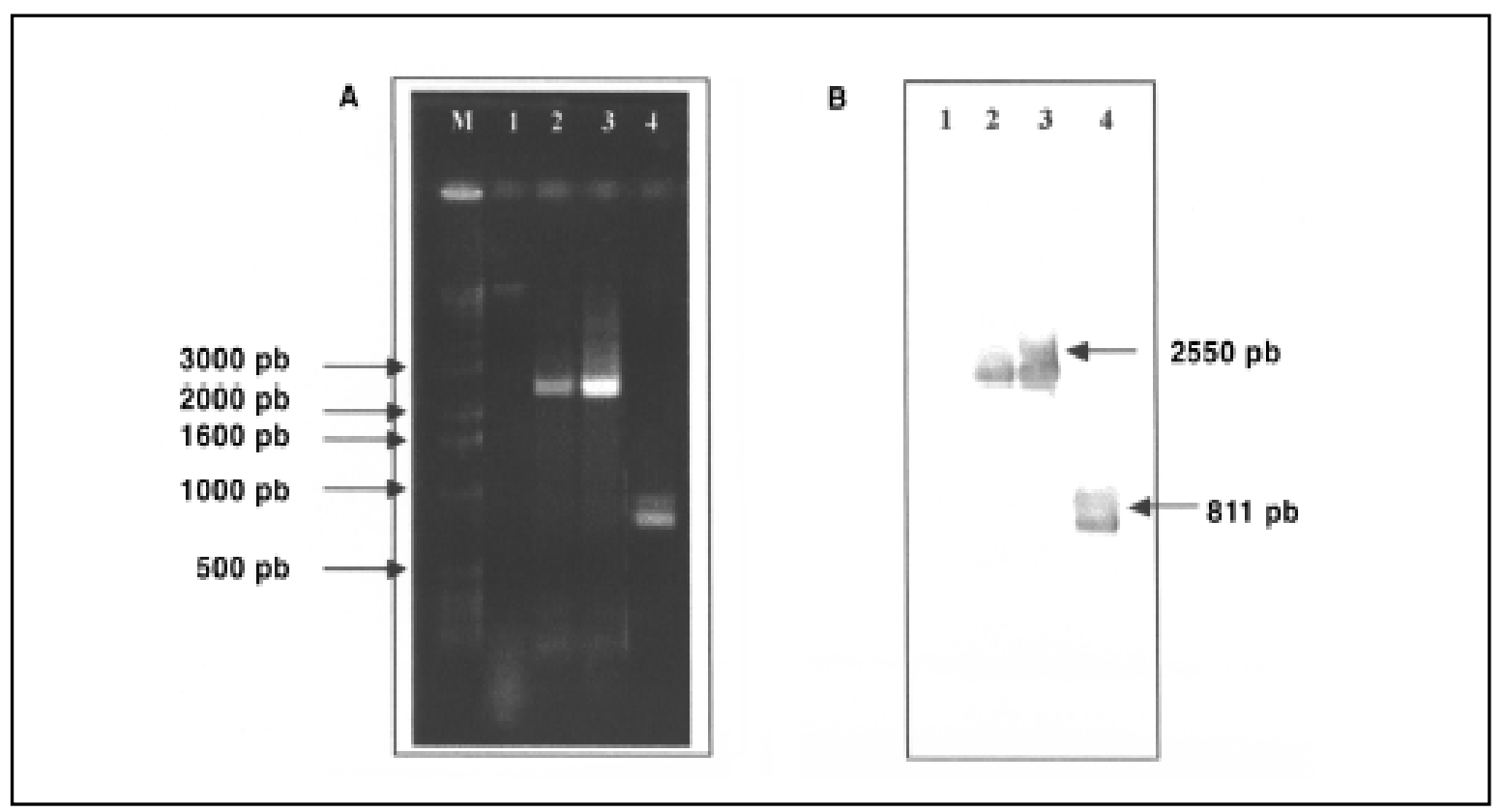

Figura 3. PCR para calcular el tamaño del inserto de GOGAT del clon aislado de la genoteca de la cepa Dd2. Se utilizó como plantilla ADN del fago recombinante. Los productos de PCR se analizaron mediante electroforesis horizontal en geles de agarosa al $1 \%(A)$ y se transfirieron a una membrana de nylon, la cual se hibridizó con una sonda biotinilada específica para GOGAT (B).

M: Ladder $1 \mathrm{~kb}$; 1) ADN $\lambda$ Zapll-GOGAT; 2 y 3) producto de amplificación con los oligonucleótidos de los promotores T3 y T7; 4) producto de amplificación con oligonucleótidos internos de GOGAT.

cuyos tamaños son: $1.647,789$ y 437 pb. Por su parte, la digestión con Notl-Xhol produjo un sólo fragmento de $2.457 \mathrm{pb}$ (figura 7). Estos resultados concuerdan con el análisis de restricción teórico que se hizo con estas enzimas sobre la secuencia codificante del gen completo de Pfmyo A informada en el GENBANK (AF105117).

\section{Discusión}

La construcción de las genotecas de ADNc de $P$. falciparum es una herramienta excelente para aislar genes que se expresan en estadios específicos de desarrollo del parásito $P$. falciparum. En este trabajo se construyó una genoteca de ADNc en el vector de expresión procariótico $\lambda$ ZipLox, que produce clones direccionados, lo que permite tener un rápido acceso a transcritos abundantes, a la vez que hace posible la subclonación en sistemas de expresión. Las genotecas construidas en vectores derivados del fago $\lambda$ presentan la ventaja de tener una alta eficiencia de empaquetamiento in vitro y produce alta densidad de fagos, factores importantes para la selección de transcritos poco abundantes.

En la genoteca se aislaron clones de genes de copia única como actina y CaM. Se aisló también un clon para el gen de la enzima GOGAT. La actina y la CaM son proteínas que cumplen papeles fundamentales en los eventos de fuerza que ocurren durante el ciclo de vida del parásito. Los genes completos de estas proteínas ya se han informado y es de especial importancia tener los clones de ADNc que pueden usarse para su expresión. Por su parte, GOGAT es una enzima que ha despertado un gran interés ya que podría ser un excelente blanco terapéutico para la malaria. Esta enzima no se encuentra en el humano; su actividad se ha informado en microorganismos como E. coli y Azospirilum brasilense, en levaduras como Sacharomyces cerevisiae y en plantas superiores. En $P$. falciparum, la L-glutamina es un sustrato indispensable para el crecimiento in vitro del parásito. En trabajos previos realizados en el 


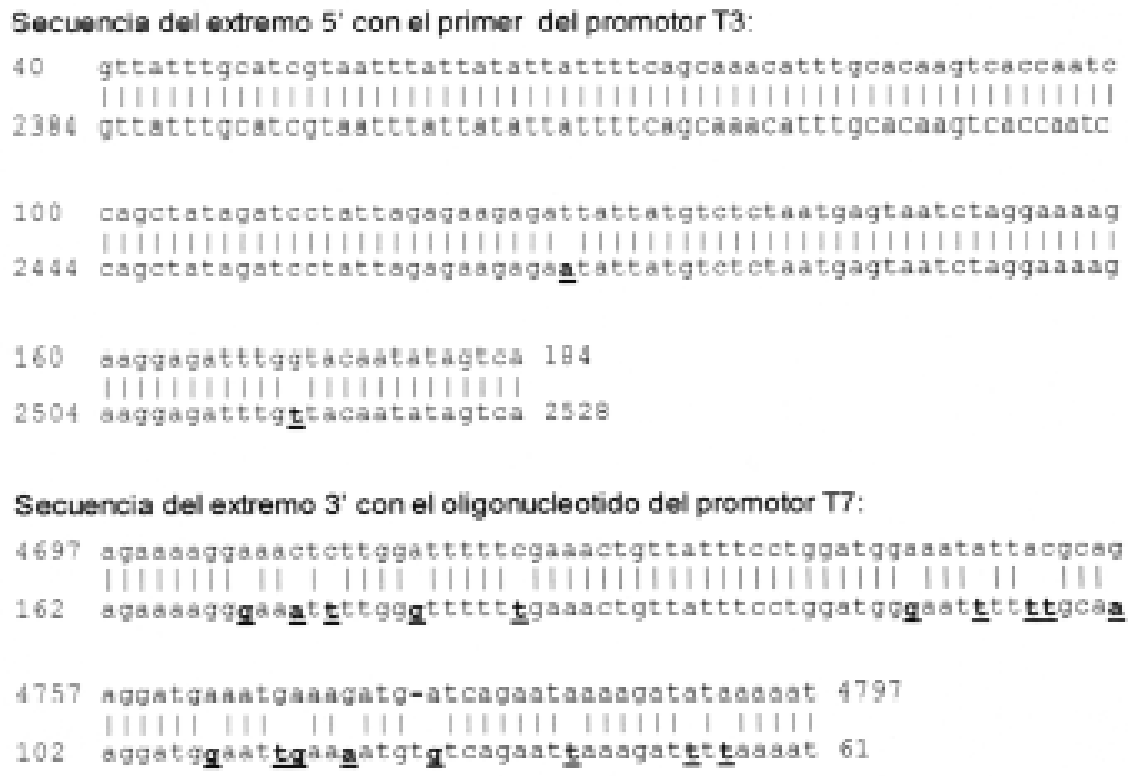

Figura 4. Alineamiento de la secuencia de nucleótidos de los extremos $5^{\prime}$ y $3^{\prime}$ del inserto de GOGAT clonado en la genoteca de la cepa Dd2 y de la secuencia codificante de NADH-GOGAT de $P$. falciparum (número de acceso al GENBANK Y17045.1). Las bases subrayadas y señaladas en negrilla indican diferencias entre las secuencias. Los huecos (gaps) presentes en las secuencias se indican con un guión.

Laboratorio de Bioquímica del INS, se aisló una proteína de $36 \mathrm{kDa}$ (que, por trabajos que conocemos ahora, debía ser un producto de degradación), cuya secuencia presentó una alta homología con la enzima GOGAT de origen vegetal. Recientemente, se informó en el GENBANK la secuencia codificante del gen de GOGAT de $P$. falciparum, que posee un tamaño de $9.720 \mathrm{pb}$. A pesar de ello, no se sabe nada acerca del gen ni de la proteína; tampoco se ha definido si la enzima está activa en el parásito. Por lo anterior, es de gran importancia la obtención de clones de ADNc de GOGAT, que servirían como herramienta para la caracterización molecular del gen y para los estudios de funcionalidad de la proteína.

En este trabajo se rastreó otra genoteca de ADNc representativa de los estadios asexuales de la cepa Dd2 de $P$. falciparum. En ella se identificó la presencia de los clones de actina I, CaM, GOGAT, las miosinas Pfmyo A, Pfmyo B y Pfmyo $C$ y se aislaron clones de GOGAT y de Pfmyo A.
Los insertos de GOGAT y Pfmyo A clonados se aislaron haciendo una reacción de PCR con oligonucleótidos universales que tienen sitios de anillaje en regiones del vector que flanquean los sitios de clonación, como se describió en la metodología. El clon de GOGAT aislado de la genoteca de la cepa FCB2 tiene un inserto de $1.365 \mathrm{pb}$. El clon de GOGAT aislado de la genoteca de la cepa Dd2 tiene un inserto de 2.413 pb; su identidad se confirmó por secuenciación y comprende las posiciones 2.384 y 4.797 de la secuencia codificante del gen. A pesar de que los clones de GOGAT encontrados en ambas genotecas parecen no tener la secuencia codificante completa (9.720 pb), este resultado es muy interesante, ya que se logró obtener un fragmento muy grande del gen que está expresándose durante el estadio de vida sexual del parásito. Un ARNm de 9.720 pb, como el de GOGAT, es difícil de aislar en genotecas de ADNc y el clon obtenido de la genoteca de la cepa Dd2 es el fragmento aislado más grande. Los 


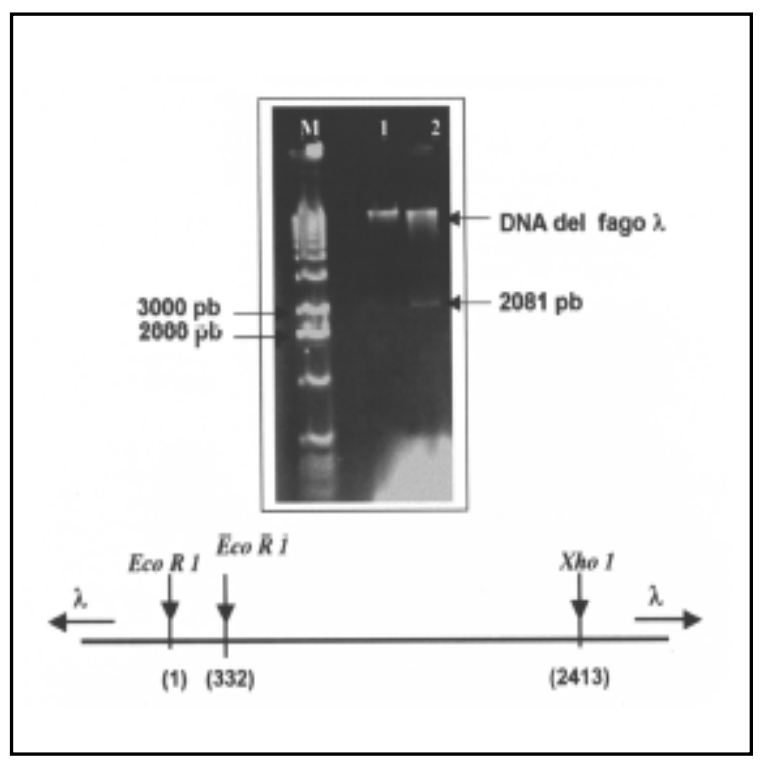

Figura 5. Digestión con enzimas de restricción del ADN del fago recombinante $\lambda$ Zapll-GOGAT. Se hizo corte con las enzimas de restricción $E c o R I$ y $X h o l$ al vector con el inserto. El análisis de restricción teórico que se realizó sobre la secuencia codificante de GOGAT indica que deben liberarse dos fragmentos, uno de $2.081 \mathrm{pb}$ y otro de $332 \mathrm{pb}$ (que se localiza en el mismo lugar del ARN del fago). Los resultados se analizaron mediante electroforesis en agarosa al 1,5\% en TBE $1 X$.

M: Ladder de $1 \mathrm{~Kb}$. 1) ADN $\lambda$ Zapll-GOGAT sin digerir; 2) ADN $\lambda$ Zapll-GOGAT digerido con las dos enzimas.

resultados obtenidos en trabajos realizados en nuestro laboratorio mediante experimentos de inmunotransferencia con un anticuerpo policlonal desarrollado contra GOGAT han permitido la detección de polipéptidos con tamaños de 70 y $160 \mathrm{kDa}$, las cuales muy probablemente correspondan a productos de degradación de la proteína GOGAT. Los clones de GOGAT aislados en este estudio constituyen una valiosa herramienta para la caracterización de la proteína, ya que la expresión de estos fragmentos de ADNc serviría en la producción de anticuerpos policlonales o monoclonales, que podrían emplearse para determinar la actividad de la proteína en el parásito.

Otro clon que se aisló en la genoteca de ADNc de la cepa Dd2 del parásito fue el de la miosina Pfmyo A. Ésta es otra proteína que se ha propuesto como componente de un motor actomiosina que estaría generando la fuerza requerida para la invasión del parásito al eritrocito.
El tamaño del inserto de Pfmyo A clonado se estimó en aproximadamente $2.500 \mathrm{pb}$, que concuerda con el calculado para la secuencia codificante completa, que es de $2.457 \mathrm{pb}$. Los experimentos con enzimas de restricción permitieron confirmar este tamaño.

El hallazgo de un clon de ADNc completo de Pfmyo A constituye un paso importante para futuros estudios en el parásito. Este es el primer informe de un clon de ADNc completo de Pfmyo A. La secuencia del gen informada en el GENBANK (AF105117) se logró a partir de un producto de amplificación por PCR con un oligonucleótido antisentido correspondiente a la cola y un oligonucleótido sentido correspondiente a un motivo conservado en el dominio de cabeza de las miosinas. La búsqueda de la secuencia de este producto en la base de datos del proyecto del genoma de $P$. falciparum permitió completar la secuencia del ARNm. Pfmyo A muestra un alto grado de homología con las miosinas de clase XIV de Toxoplasma gondii previamente identificadas $(25,26)$. La proteína tiene una masa molecular de $90 \mathrm{kDa}$, lo que la hace uno de los motores moleculares más pequeños que se han identificado hasta ahora. Las miosinas clase XIV no poseen los motivos IQ que han sido implicados en la unión a proteínas reguladoras como la calmodulina y las proteínas relacionadas con la calmodulina; sin embargo, poseen aminoácidos conservados que podrían representar una forma diversa de motivos IQ (18). Este clon de ADNc de Pfmyo A constituye una valiosa herramienta para realizar estudios de localización, determinar particularidades de la proteína que la diferencian de las miosinas del hospedero y para llevar a cabo estudios fisiológicos y funcionales que permitan definir su papel durante la invasión.

En este trabajo también se identificó la presencia de clones para los genes de Pfmyo B y Pfmyo C en la genoteca de ADNc de los estadios de vida asexual de la cepa Dd2 del parásito. Es de gran importancia que otras miosinas en el parásito también se estén expresando durante el estadio asexual. El aislamiento de clones con genes de estas miosinas permitiría definir las actividades de fuerza que pueden estar progresando a lo largo del desarrollo asexual del parásito; por 

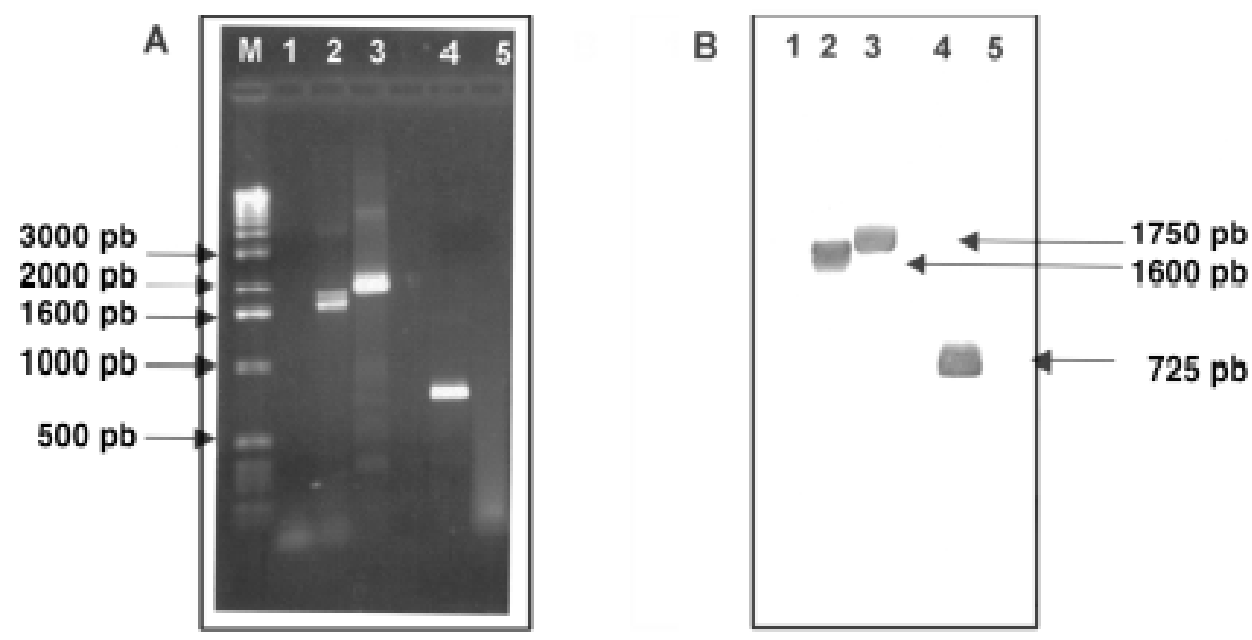

Figura 6. PCR para calcular el tamaño del inserto de Pfmyo A del clon aislado de la genoteca de la cepa Dd2. Se utilizó como plantilla ADN del fago recombinante. Los productos de PCR se analizaron mediante electroforesis horizontal en geles de agarosa al $1 \%(A)$ y se transfirieron a una membrana de nylon, la cual se hibridizó con una sonda biotinilada específica para Pfmyo A (B).

M: Ladder $1 \mathrm{~kb}$; 1) amplificación con los oligonucleótidos de los promotores T3 y T7; 2) producto de amplificación con T3PfmyoA(s); 3) producto de amplificación con T7-PfmyoA (as); 4) producto de amplificación con oligonucleótidos internos PfmyoA(s)-Pfmyo A(as); 5) control negativo del PCR sin ADN.
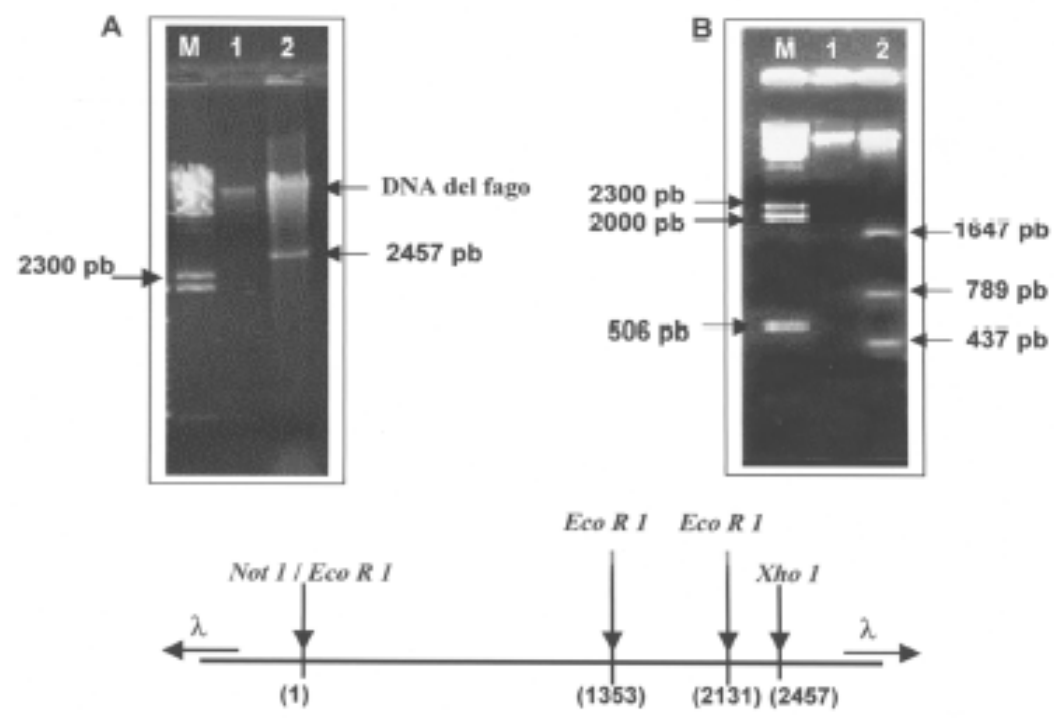

Figura 7. Digestión con enzimas de restricción Notl/EcoRI y Xhol del ADN del fago recombinante $\lambda$ Zapll-Pfmyo A. El resultado se analizó mediante electroforesis en agarosa al 1,5\%.

M: Lambda HindlI; ADN $\lambda$ Zapll-Pfmyo A sin digerir; 2. ADN $\lambda$ Zapll-Pfmyo A digerido con las dos enzimas. Primer panel, digestión con Notl y Xhol, produjo una banda de $2.457 \mathrm{pb}$ que corresponde al inserto completo de Pfmyo A. Segundo panel, digestión con EcoRl y Xhol, produjo tres fragmentos con los tamaños: 1.647, 789 y 437 pb. 
tanto, se continuará trabajando en el aislamiento y confirmación de estos clones como parte de otro trabajo de investigación del Laboratorio de Bioquímica del INS.

\section{Agradecimientos}

Este trabajo fue financiado por el Instituto Nacional de Salud, la Universidad Nacional de Colombia y el Instituto Colombiano para el Desarrollo de la Ciencia y la Tecnología "Francisco José de Caldas" COLCIENCIAS, proyecto BID-Colciencias 2104-04170-95.

\section{Referencias}

1. Wasserman M, Alarcón C, Mendoza PM. Effects of $\mathrm{Ca} 2+$ on the asexual cell cycle of Plasmodium falciparum. Am J Trop Med Hyg 1982;31:711-7.

2. Wasserman M, Vernot SP, Mendoza P. Role of calcium and erythrocyte cytoskeleton phosphorylation in the invasion of Plasmodium falciparum. Parasitol Res 1990;76:681-8

3. Tinjacá C, Wasserman M. Caracterización parcial de la CaM de Plasmodium falciparum. Biomédica 1995; 15:206-14.

4. Cohen P, Klee CB, editors. Calmodulin: molecular aspects of cellular regulation. Volumen 5. Amsterdam: Elsevier Press; 1988.

5. Rasmussen CD, Means AR. Increased calmodulin affects cell morfology and messenger RNA levels of cytoskeletal protein genes. Cell Motility and Cytoskeleton 1992;21:45-57.

6. Bachs O, Agell N, Carafoli E. Calmodulin and calmodulin binding-proteins in the nucleus. Cell Calcium 1994;16:289-96.

7. Orr GA, Tanowitz HB, Wittner M. Trypanosoma cruzi stage expression of clamodulin-binding proteins. Exp Parasitol 1992;74:127-33.

8. Vera V. Aislamiento y caracterización de PUCaM en Plasmodium falciparum (tesis). Santa Fé de Bogotá: Universidad Nacional de Colombia; 1999.

9. Beny AG, Boland MJ. Enzymes of nitrogen metabolism in legume nodules. Purification and properties of NADH dependent glutamate synthase from lupine nodules. Eur J Biochem 1977;79:355-62.

10. Sherman LW, Peterson E, Tanigoshi L, Ting IP. The glutamate dehydrogenase of Plasmodium falciparum lophurae (avian malaria). Exp Parasitol 1971;29:433-9.

11. Roth EF, Raventos-Suarez C, Perkins M, Nagel RN. Gluthathione stability and oxidative stress in $P$. falciparum infection in vitro: responses of normal and G6PD deficient cell. Biochem Biophys Res Commun 1982;109:335-61.
12. Elford BC, Pinches RA. Inducible transport systems in the regulation of parasite growth in malaria infected. Biochem Soc Trans 1992;20:790-6.

13. Forero de Lleras C. Proteínas de unión a actina en Plasmodium falciparum (tesis). Santa Fe de Bogotá: Universidad Nacional de Colombia; 1996.

14. Pinder JC, Fowler RE, Dluzewski AR, Bannister LH, Lavin FM, Mitchell GH, Wilson RJ, Gratzer WB. Actomyosin motor in the merozoite of the malaria parasite Plasmodium falciparum: implications for red cell invasion. J Cell Sci 1998;111:1831-9.

15. Bement WM, Hasson T, Wirth JA, Cheney RE, Mooseker MS. Identification and overlapping expression of multiples unconventional myosin genes in vertebrate cell types. Proc Natl Acad Sci USA 1994;91:6549-53.

16. Pinder JC, Fowler RE, Bannister LH, Dluzewski AR, Mitchell GH. Motile systems in malaria merozoites: How is the red blood cell invaded? Parasitol Today 2000; $16: 240-5$.

17. Dame JB, Ranot DE, Bourke PFI. Current status of the Plasmodium falciparum genome project. Mol Biochem Parasitol 1996;79:1-12.

18. Hettman C, Herm A, Geiter A, Frank B, Shwarz E, Soldati T, Soldati $\mathbf{D}$. A dibasic motif in the tail of a class XIV apicomplexan myosin is an essencial determinant of plasma membrane localization. Mol Biol Cell 2000;11: $1385-400$.

19. Trager W, Jensen JE. Human malaria parasites in continuous culture. Science 1976;193:673-5.

20. Rojas MO, Wasserman MM. Stage-specific expression of the calmodulin gene in Plasmodium falciparum. J Biochem 1995;118:1118-23.

21. Gubler U, Hoffman BJ. A simple and very efficient method for generating cDNA libraries. Gene 1983;25: 263.

22. Clark L, Carbon J. A colony bank containing synthetic ColE1 hybrids representative of the entire $E$. coli genome. Cell 1976;9:91-9.

23. Chakrabarti D, Reddy GR, Dame JB, Almira EC, Laipis PJ, Ferl RJ, Yang TP, Rowe TC, Schuster SM. Analysis of expressed sequence tags from Plasmodium falciparum. Mol Biochem Parasitol 1994; 66:97-104.

24. Sanger F, Nicklen S, Couson AR. DNA sequencing with chain terminating inhibitors. Proc Natl Acad Sci USA 1977;74:5463-7.

25. Heintzelman MB, Schwartzman JD. A novel class of unconventional myosins from Toxoplasma gondii. J Mol Biol 1997;271:139-46.

26. Heintzelman MB, Schwartzman JD. Character-ization of myosin A and myosin C: two class XIV unconventional myosins from Toxoplasma gondii. Cell Motility and Cytoskeleton 1999;44:58-67. 